\title{
Article \\ Evaluation of Single-Lap and Block Shear Test Methods in Adhesively Bonded Composite Joints
}

\author{
Alec Redmann ${ }^{1, *(\mathbb{D})}$, Vinay Damodaran ${ }^{2}$, Felix Tischer ${ }^{1}$, Pavana Prabhakar ${ }^{2}$ and Tim A. Osswald $^{1}$ (D) \\ 1 Polymer Engineering Center, Department of Mechanical Engineering, University of Wisconsin-Madison, \\ Madison, WI 53706, USA; felix.tischer@rwth-aachen.de (F.T.); tosswald@wisc.edu (T.A.O.) \\ 2 Department of Civil \& Environmental Engineering, University of Wisconsin-Madison, \\ Madison, WI 53706, USA; vdamodaran@wisc.edu (V.D.); pavana.prabhakar@wisc.edu (P.P.) \\ * Correspondence: aredmann2@wisc.edu
}

check for updates

Citation: Redmann, A.; Damodaran, V.; Tischer, F.; Prabhakar, P.; Osswald, T.A. Evaluation of Single-Lap and Block Shear Test Methods in Adhesively Bonded Composite Joints. J. Compos. Sci. 2021, 5, 27. https://doi.org/10.3390/jcs5010027

Received: 29 December 2020 Accepted: 12 January 2021 Published: 15 January 2021

Publisher's Note: MDPI stays neutral with regard to jurisdictional clai$\mathrm{ms}$ in published maps and institutional affiliations.

Copyright: () 2021 by the authors. Licensee MDPI, Basel, Switzerland. This article is an open access article distributed under the terms and conditions of the Creative Commons Attribution (CC BY) license (https:// creativecommons.org/licenses/by/ $4.0 /)$.

\begin{abstract}
Adhesive bonding is increasingly being used for composite structures, especially in aerospace and automotive industries. One common joint configuration used to test adhesive strength is the single-lap shear joint, which has been widely studied and shown to produce significant normal (peeling) stresses. When bonding composite structures, the normal stresses are capable of causing delamination before the adhesive bond fails, providing inconclusive engineering data regarding the bonding strength. An alternative test is the block shear joint, which uses a shorter sample geometry and a compressive-shear loading to reduce normal stresses. Analytical models proposed by Goland and Reissner and Hart-Smith are used to compare the edge-bending moment for the two joint configurations. The stress distributions along the bondline are also compared using finite element analysis. Experimental tests are conducted to evaluate these analyses and the failure modes of each configuration are recorded. Block shear samples demonstrate a joint strength over $100 \%$ higher than single-lap shear specimen bonded with the same adhesive material. The lower joint strength measured in single-lap shear is found to be potentially misleading due to delamination of the composite adherend.
\end{abstract}

Keywords: joining; bonding; adhesive; single lap shear; block shear; shear testing

\section{Introduction}

As designers and engineers continue to push the boundaries of high-performance design, fiber reinforced plastics (FRP) are increasingly finding use in structural applications due to their light weight and superior mechanical properties. Many of these applications, especially in the aerospace and automotive industries, require geometrical complexity, multiple components, and multiple materials. These requirements lead to a need for assembly and joining elements during manufacturing - typically mechanical fasteners or adhesives. Adhesive bonding is the generally preferred technique when manufacturing FRP structures for a multitude of reasons. Unlike mechanical fasteners, adhesive bonding does not require material removal, which reduces stress concentrations and stress cracking introduced by the drilling and installation of fasteners. The installation of mechanical fasteners may lead to additional problems of uneven load distribution and stress concentrations at the threads [1], and slight pitch differences must be incorporated to improve fatigue strength and prevent loosening of the fastener [2]. Adhesive bonding also avoids a weight penalty that is incurred by mechanical fasteners, better supporting the goal of a lightweight design, and galvanic corrosion is minimized, which can be responsible for more than $20 \%$ of the maintenance costs in aerospace and automotive applications [3-5].

Adhesive bonds are designed to perform primarily in a state of shear, where the forces act parallel to the cross-section of the adhesive in opposite directions of its plane [6]. Shear testing is used to determine the maximum loads that a bonded component can resist when designed accordingly. In these tests, shear forces are applied through torsion, tension, 
or compression. Tension shear testing is among the most commonly used due to the simple test geometry, unlike torsion shear testing, which requires more complex sample geometry and manufacturing processes. Tensile single-lap shear joints are a widely used and cited test in the literature for comparing adhesion properties. One challenge presented with this test is the complex loading conditions experienced at the adhesive-adherend interface, which has been well-reported to have a significant impact on the results, potentially leading to incorrect conclusions regarding the strength of the studied bond $[7,8]$.

Contributing to this challenge with FRP single-lap shear tests is the uneven deformation and shear stress in the adhesive. The tensile stress in the adherend decreases along the overlap from a maximum at the start of the overlap nearest the edge where the load is applied, to zero stress at the far edge. Thus, the tensile strain at the adhesive-adherend interface must also decrease progressively along the joint length, leading to the distorted deformation as seen in Figure 1. This effect is known as differential shear and causes the shear stress in the adhesive to concentrate at the overlap edges under high loads [9].

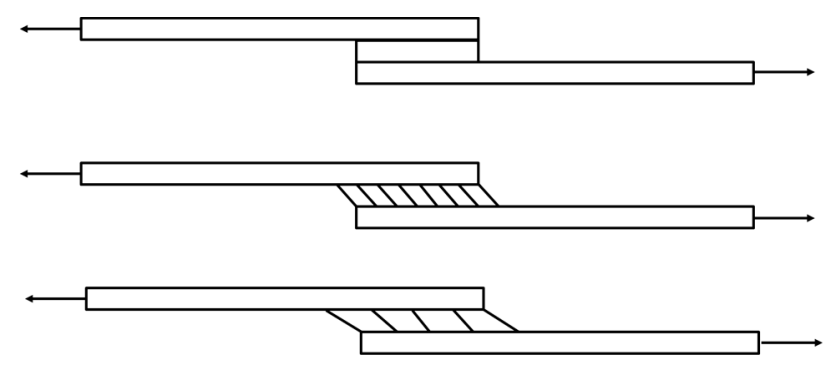

Figure 1. Schematic lap shear specimen at low loads and no adhesive elongation (top), intermediate loads with even adhesive elongation and shear stress (center), and at high loads with uneven adhesive elongation and shear stress (bottom).

Another complication with single-lap shear joints is the eccentricity in the load path, which causes bending and normal forces in the adhesive zone, referred to as peeling forces (Figure 2). In the case of a joint with metal adherends, these forces would result in adhesive peeling. However, with FRP adherends the inter-laminar tensile strength is significantly lower than the peel strength of structural adhesives, and these peel forces often lead to failure caused by the delamination of the composite fiber layers [10]. As an approach to overcome the drawbacks of single-lap shear testing, double-lap shear joints have been used. Although the bending moment is minimized, it has been found that adherends still experience internal bending [11,12]. Because of these effects, the failure observed in FRP lap shear testing is rarely associated with the failure of the adhesive in shear.

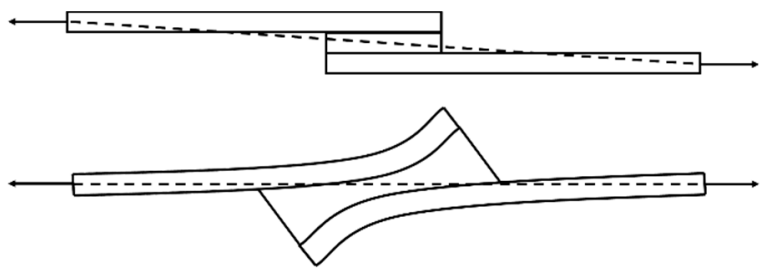

Figure 2. Representation of lap shear bending due to eccentricity in the load path.

Block shear testing is an alternative to single-lap shear testing, which essentially removes the eccentricity and subsequent bending moment. The specimen geometry for block shear is similar to single-lap shear, differing only in the shorter length and increased thickness of the adherends. In contrast to the single-lap shear tests, the shear forces are applied through compression, using a specialized fixture. The standard ASTM geometry and test configuration for block shear tests and single-lap shear tests are compared in Figure $3[13,14]$. 

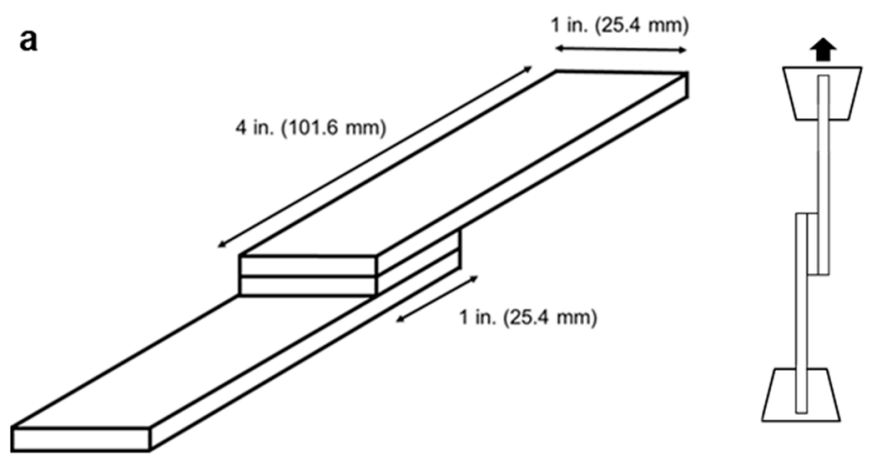

b
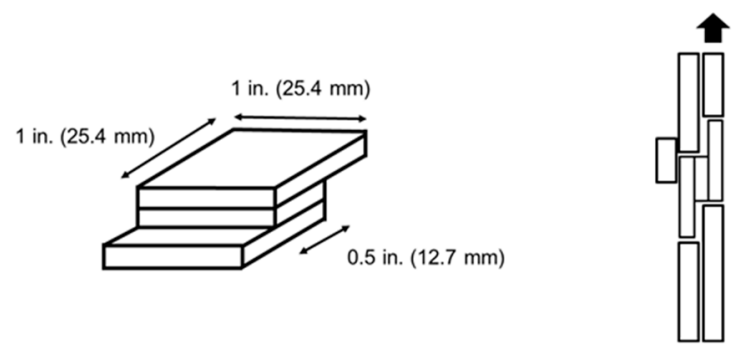

Figure 3. Dimensions and test configuration for (a) a single-lap shear specimen according to ASTM D5868 and (b) a block shear specimen according to ASTM D4501.

The aim of this study is to evaluate the differences in stress state by modifying existing models for single-lap shear tests to the block shear test. Two beam model solutions for adhesively bonded single-lap joints, one proposed by Goland and Reissner [15], and a modification by Hart-Smith [16] are introduced. These models are used as an analytical comparison for the block shear test geometry and boundary conditions. Finite element models are also used to provide a numerical comparison for the two test conditions. Finally, FRP samples are manufactured and tested in single-lap shear and block shear for an experimental comparison using three different joining materials.

\section{Analytical Models for Adhesively Bonded Joints}

When the lap shear geometry is subjected to tension, the bending moment provides the most significant contribution to the stress magnitude. In order to accurately predict the adhesive stresses in the overlap edge region, the edge moment must be determined. The following analyses of bonded joints are based on Kirchhoff-Love plate theory for thin plates in cylindrical bending [17], with the governing Equation:

$$
\frac{d^{2} w}{d x^{2}}=-\frac{M}{E * J}=-\frac{M}{D}
$$

where $w$ is the lateral deflection and $D$ defines the flexural rigidity with the modulus, $E$ and polar moment of inertia, J. The moment per unit width at the ends of the adherend overlap, $M_{0}$, in this beam model is defined as:

$$
M_{0}=\left(\frac{P t}{2}\right) k
$$

where $P$ is the applied tensile load per unit width, $t$ is the adherend thickness, and $k$ is a bending-moment factor. The bending moment factor, $k$, is used to represent the edgebending moment and provide a simplified insight into the stress state at the edge.

Goland and Reissner (GR) were the first to analyze a single-lap joint considering the rotation of the adherends and brought attention to the impact these bending deflections have on the peel and shear stresses in the adhesive layer [15]. Their original analysis 
modelled the lap joint as a single, homogeneous beam, as shown in the schematic model in Figure 4, with key terms and coordinate systems defined. Their original analysis neglected adhesive thickness $\left(t_{a}=0\right)$ and boundary conditions used to solve the second order differential Equation for deflection (Equation (1)) are as follows:

$$
\begin{array}{ll}
\text { I. } & w_{1}\left(x_{1}=0\right)=0 \\
\text { II. } & w_{1}\left(x_{1}=l\right)=w_{2}\left(x_{2}=-c\right) \\
\text { III. } & \frac{d w_{1}\left(x_{1}=l\right)=\frac{d w_{2}\left(x_{2}=-c\right)}{d x_{2}}}{d x_{2}} \\
\text { IV. } & w_{2}\left(x_{2}=0\right)=0
\end{array}
$$

giving the solution:

$$
M_{0}=\left(\frac{P t}{2}\right) \frac{1}{1+2 \sqrt{2} \tanh \left(\frac{\xi c}{2 \sqrt{2}}\right)}
$$

where $c$ is the overlap length from the centerline of the joint, $\xi^{2}=\frac{P}{D}$, and $D$ is the unit-width adherend bending stiffness:

$$
D=\left(\frac{E}{1-v^{2}}\right) \frac{t^{3}}{12}
$$

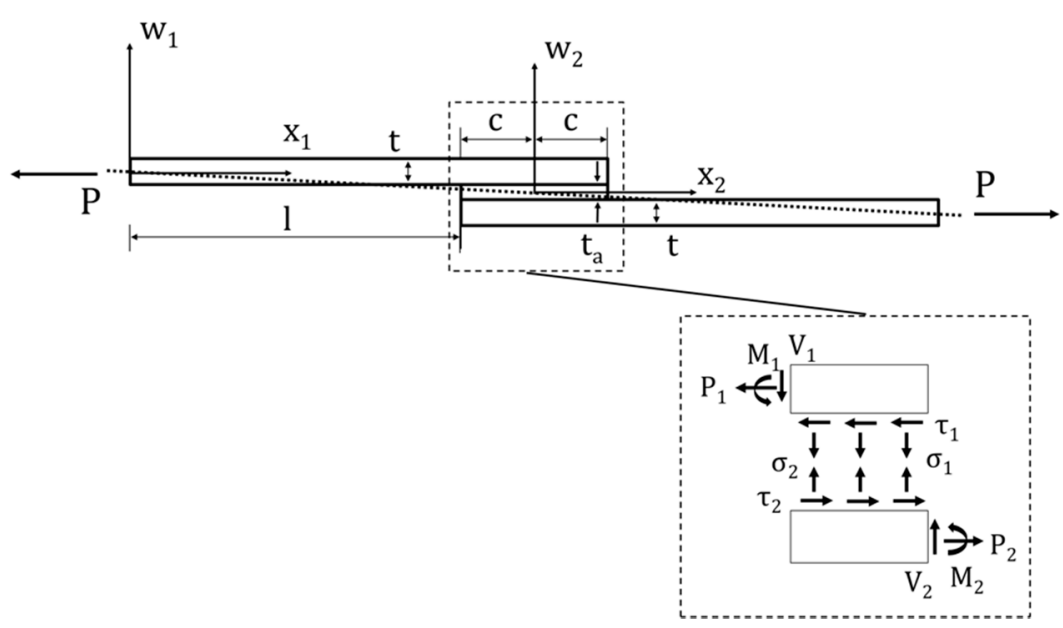

Figure 4. The reference system and critical terms used to model the lap shear joint. Origin for the coordinate system (1) is located at the center of the upper adherend and origin for coordinate system (2) is located at the centroid of the joint.

This solution takes the form of Equation (2), where the bending-moment factor is defined by Goland and Reissner $\left(k_{G R}\right)$ :

$$
k_{G R}=\frac{1}{1+2 \sqrt{2} \tanh \left(\frac{\xi c}{2 \sqrt{2}}\right)}
$$

Goland and Reissner's derivation assumes that the overlap region is deformed as a single block with a uniform stiffness. Hart-Smith (HS) suggested an improvement by considering adhesive plasticity and including the effect of adherend thickness, $t_{a}$ [16]. 
The boundary conditions used in the Hart-Smith analysis considered joint deflection only in the unbonded section of the adherend:

$$
\begin{array}{ll}
\text { I. } & w_{1}\left(x_{1}=l\right)=w_{2}\left(x_{2}=-c\right) \\
\text { II. } \quad \frac{d w_{1}\left(x_{1}=l\right)}{d x_{1}}=\frac{d w_{2}\left(x_{2}=-c\right)}{d x_{2}} & \\
\text { III. } \quad \frac{d^{2} w_{1}\left(x_{1}=l\right)}{d x_{1}^{2}}=\frac{d^{2} w_{2}\left(x_{2}=-c\right)}{d x_{2}^{2}} \\
\text { IV. } \quad \frac{d^{4} w_{1}\left(x_{1}=l\right)}{d x_{1}^{4}}=\frac{d^{4} w_{2}\left(x_{2}=-c\right)}{d x_{2}^{4}}=\frac{t+t_{a}}{2 D} \frac{d \tau\left(x_{2}=-c\right)}{d x_{2}}
\end{array}
$$

which, when reducing non-significant terms, gives the full expression for edge moment, $M_{0}$ :

$$
M_{0}=P\left(\frac{t+t_{a}}{2}\right) \frac{1+\frac{t_{a}}{t}}{1+\frac{\xi \mathcal{G}}{\tanh (\xi l)}+\frac{\xi^{2} c^{2}}{6}}
$$

where the edge bending-moment factor is defined by Hart-Smith $\left(k_{H S}\right)$ as:

$$
k_{H S}=\frac{1+\frac{t_{a}}{t}}{1+\frac{\xi^{c} c}{\tanh (\xi l)}+\frac{\xi^{2} c^{2}}{6}}
$$

For large $\xi l$, this expression can be $\operatorname{simplified~by~} \tanh (\xi l) \approx 1$, and Equation $(7)$ becomes:

$$
k_{H S}=\frac{1+\frac{t_{a}}{t}}{1+\xi c+\frac{\xi^{2} c^{2}}{6}}
$$

Next, considering the block shear specimen, the conditions of the experimental set-up constrict the faces of the adherends with the compression fixture. This essentially eliminates any of the out-of-plane bending and reduces the eccentricity to zero. The two analytical models for single-lap shear are compared to block shear in Figure 5. The eccentricity decreases for both the GR and HS models, with an increase in the non-dimensional overlap term $\xi c$, though only the HS model reduces to zero and is more accurate when observing eccentricity in bonded materials where the adherend has a much higher stiffness than the adhesive.

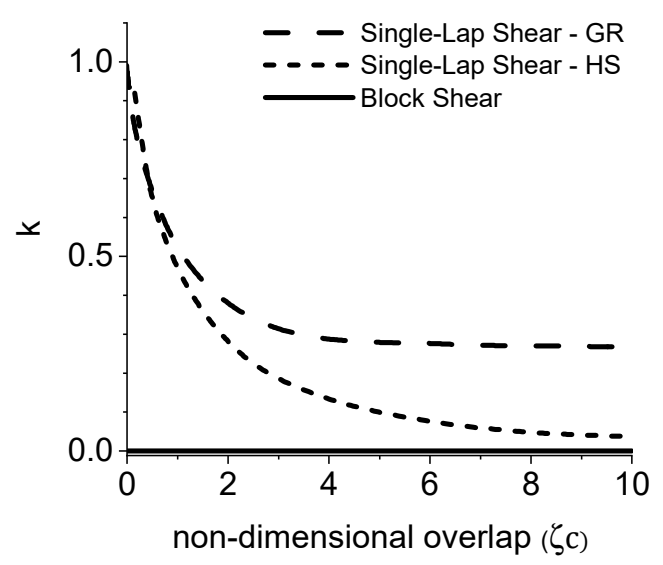

Figure 5. Edge bending-moment factor $k$ for single-lap shear geometry as determined by Goland and Reissner (GR) and Hart-Smith (HS) compared to block shear.

It is important to note, that several corrections have been developed for the GR and HS models, including those by Oplinger [18], and more recently by Li and Lee-Sullivan [19]. While the variations of these models provide improved solutions, the original GR and HS models continue to be frequently cited in the literature and provide a satisfactory representation of the edge bending-moment for the purposes of this study. 


\section{Finite Element Model}

A finite element analysis was performed using the commercial software package ABAQUS to study the shear and peel stresses at the bondline in both single-lap shear and block shear tests. To simplify the analysis, a 2D model was determined to be sufficient to predict the shear and peeling stresses along the length of the bondline.

\subsection{Single-Lap Shear}

The model was generated with dimensions as per ASTM D5868 [13]. Second order plane strain elements (CPE8R) were used to mesh the adherends and the adhesive material with four elements in the through-thickness direction to achieve convergence. This resulted in an element edge length of $0.25 \mathrm{~mm}$. The bonding between the adhesive and adherends was assumed to be perfect, and a tie-constraint was imposed between the two, as shown in Figure 6.

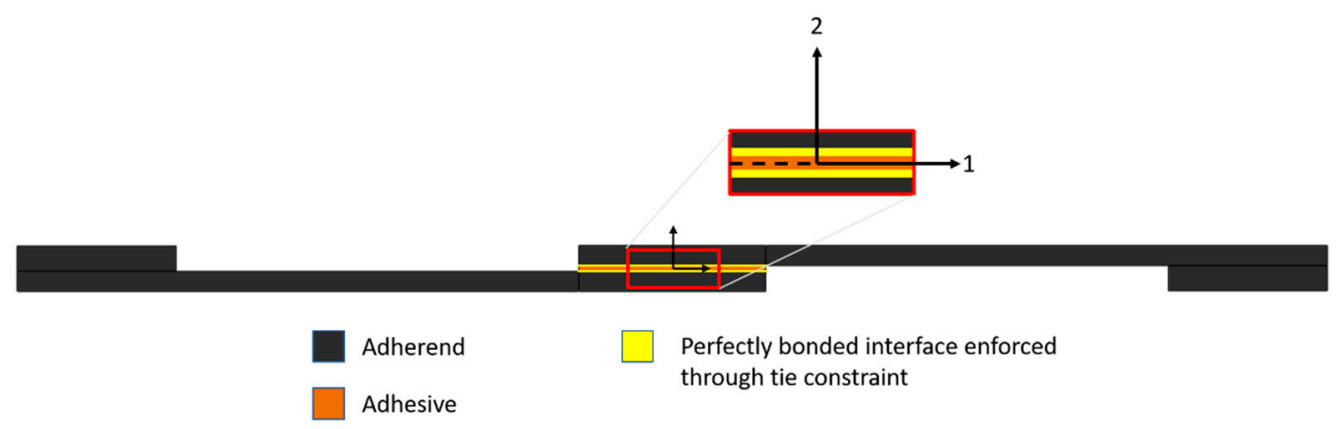

Figure 6. Single-lap shear modeled using plane strain elements in ABAQUS. A tie-constraint simulates a perfect bond between the adherend and adhesive.

A parametric study was performed to understand the effect of moduli of the adherend and adhesive on the peel and shear stresses at the bond line. The ratio between the Young's modulus of the adherend and the adhesive, or $E_{r}$ was used as a metric to study this. The adhesive was assigned a typical Young's modulus of 3.0 GPa [6] and the adherends were assigned Young's modulus values of $32.8 \mathrm{GPa}$ [20] for a representative glass fiber composite and $145 \mathrm{GPa}$ and $230 \mathrm{GPa}$ for a low-modulus and high-modulus carbon fiber composite, respectively [21]. The resulting modulus ratio values were approximated as $E_{r}=\{10,50,80\}$. The ends of both adherends were fixed in the 2- direction, with one adherend fixed in the 1- direction and the other adherend having a force of $P=1000 \mathrm{~N}$ applied to the end face. Tab geometries were added to the ends of the adherends to replicate the ASTM test procedure and maintain in-line displacement. A local coordinate system was generated to follow the nodal displacements, where the origin was centered in the adhesive and the 1- direction was along the bond line, instead of the global 1- or loading direction. This allowed for the generation of shear $\left(\mathrm{S}_{12}\right)$ and peel $\left(\mathrm{S}_{22}\right)$ stresses along the bondline.

\subsection{Block Shear}

A block shear analysis was set up similar to the single-lap shear analysis as described above. The geometry was modelled based on the suggestions from ASTM D4501 [14]. Additionally, steel blocks to apply the shear force were added, as shown in Figure 7 and a contact condition was established between the steel plates and the adherends. It is important to note that the same force $P=1000 \mathrm{~N}$ was applied for block shear, while the overlap area is half that compared to single-lap shear test. 


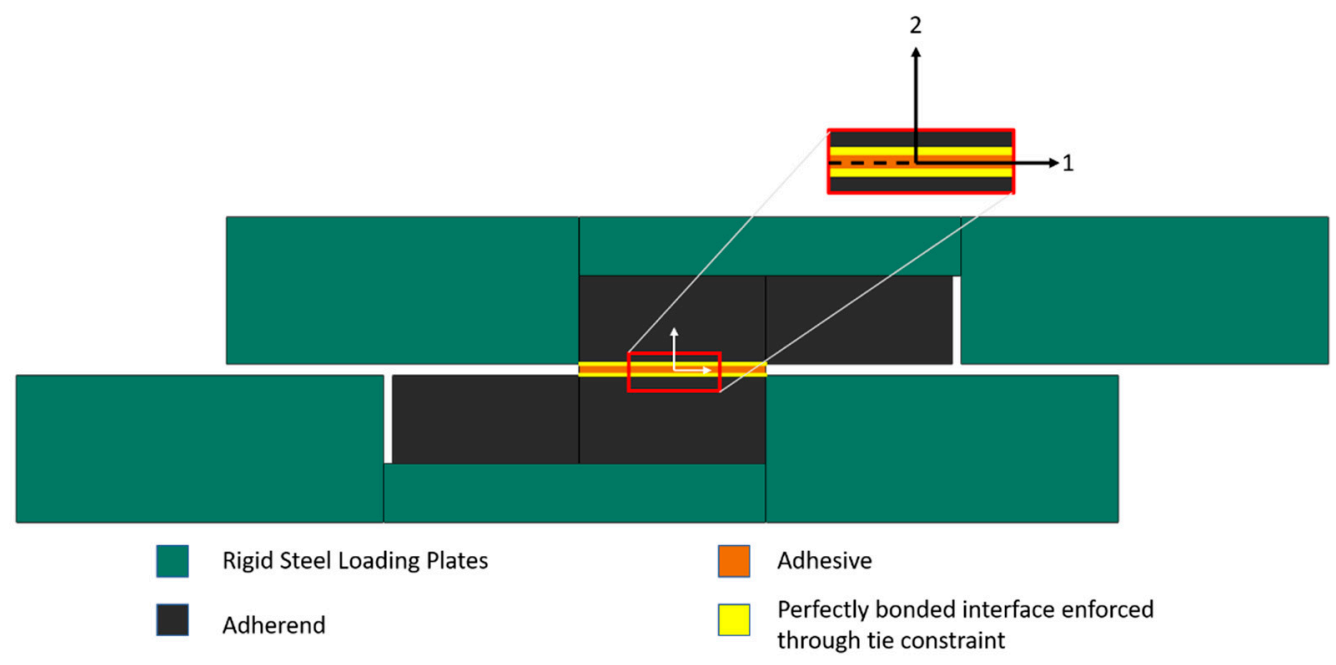

Figure 7. Block shear test modeled using plane strain elements in ABAQUS. Contact condition is applied between the adherend and the rigid steel loading plates.

\section{Experimental Methods}

\subsection{Materials}

The FRP material used in this study is a woven 7781 E-glass fiber reinforced preimpregnated material, NB-EP4030 D, produced by Mitsubishi. This is a low-temperature curing epoxy resin which is processed at $135 \pm 15^{\circ} \mathrm{C}$. The shear test specimens were manufactured with two different epoxy-based resins used for the adhesives: Scotch-Weld DP190 (3M) and EPX 82 (Carbon). The NB-EP4030 D reinforcement material used for the adherends was also used as a control in the same test geometry. The properties for these materials are listed in Table 1.

Table 1. Properties for materials used in this study.

\begin{tabular}{ccc}
\hline Material Properties & Value & Unit \\
\hline NB4030-D [20] & & \\
\hline Tensile Modulus & 32.8 & $\mathrm{GPa}$ \\
Tensile Strength & 2370 & $\mathrm{MPa}$ \\
Elongation at break & - & $\%$ \\
Glass Transition Temperature & 130 & ${ }^{\circ} \mathrm{C}$ \\
Fiber Volume Content & 60 & $\%$ \\
\hline DP190 [22] & & \\
\hline Tensile Modulus & - & $\mathrm{GPa}$ \\
Tensile Strength & 24.13 & $\mathrm{MPa}$ \\
Elongation at Break & 30 & $\%$ \\
Glass Transition Temperature & 20 & ${ }^{\circ} \mathrm{C}$ \\
\hline EPX 82 [23] & & $\mathrm{GPa}$ \\
\hline Tensile Modulus & 2.8 & $\mathrm{MPa}$ \\
Tensile Strength & 82 & $\%$ \\
Elongation at break & 5.9 & ${ }^{\circ} \mathrm{C}$ \\
\hline Glass Transition Temperature & $150-155$ &
\end{tabular}




\subsection{Manufacturing}

Both single-lap shear and block shear test samples were manufactured using the same process for each of the adhesive materials. For samples using the DP190 epoxy, the adhesive was applied in a secondary bonding process. First, the NB-EP4030 D laminate stack was first cured using a $2{ }^{\circ} \mathrm{C} / \mathrm{min}$. heating ramp to $135^{\circ} \mathrm{C}$, followed by a $60 \mathrm{~min}$. hold under vacuum pressure $(100 \mathrm{kPa})$. A 600 grit sandpaper was used to prepare the composite adherend surface for bonding, and was followed by a solvent wipe using isopropyl alcohol. An adhesive layer thickness of $0.76 \mathrm{~mm}$ was fixed using spacers and uniform pressure of $200 \mathrm{kPa}$ was applied for $24 \mathrm{~h}$.

EPX 82 was used to co-cure the composite adherends in a single thermal curing stage. This material is a dual-curing, additive manufactured epoxy-acrylate which has been previously studied for various composite bonding applications [24,25]. The EPX 82 joints were first additively manufactured to the correct thickness of $0.76 \mathrm{~mm}$ using ultraviolet light. These bonding elements were then placed between the pre-impregnated laminate stack in a mold and cured under vacuum pressure using the EP4030 cycle. The samples with the EP4030 composite material as the adhesive layer were manufactured in the same way.

For single-lap shear testing, the specimen geometry was used as specified in ASTM D5868 [13]. NEMA Grade G-10 glass epoxy laminate alignment tabs were bonded onto the specimens to ensure the centering of the specimens between the tensile testing grips. An Instron testing machine with a $30 \mathrm{kN}$ load cell was used to apply a loading rate of $13 \mathrm{~mm} / \mathrm{min}$. Eight specimens were tested for each bonding material used and the test strength $S$, was calculated from the measured maximum tensile load $F$ by:

$$
S=\frac{F}{w * l}
$$

where $w$ and $l$ are the bond width and length, respectively.

The block shear test specimens were cut to dimensions as specified by ASTM D4501 [14]. An Instron testing machine was also used to characterize the strength of the bonded samples with a $30 \mathrm{kN}$ load cell. Block shear testing requires a special fixture to clamp the sample in place, reducing the peeling effects which occur during single-lap shear tests. The block shear sample was placed in one half of the fixture, referred to as the adapter plate. A toggle clamp was then used to apply compression to the sample and prevent slipping during testing. Tension was applied to one side of the test fixture (shearing tool), while the other side remains static. Eight samples using each material for the adhesive were sheared apart until failure using a testing speed of $1.26 \mathrm{~mm} / \mathrm{min}$. The failure modes were recorded and the test strength was calculated using Equation (9). The final manufactured samples are shown in Figure 8, and the test setup is shown in Figure 9.
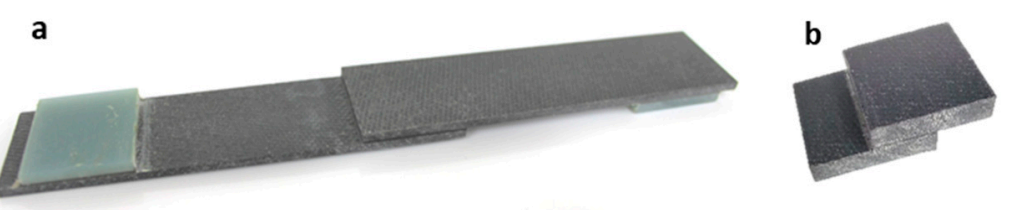

Figure 8. Manufactured (a) FRP single-lap shear specimen and (b) block shear specimen. 


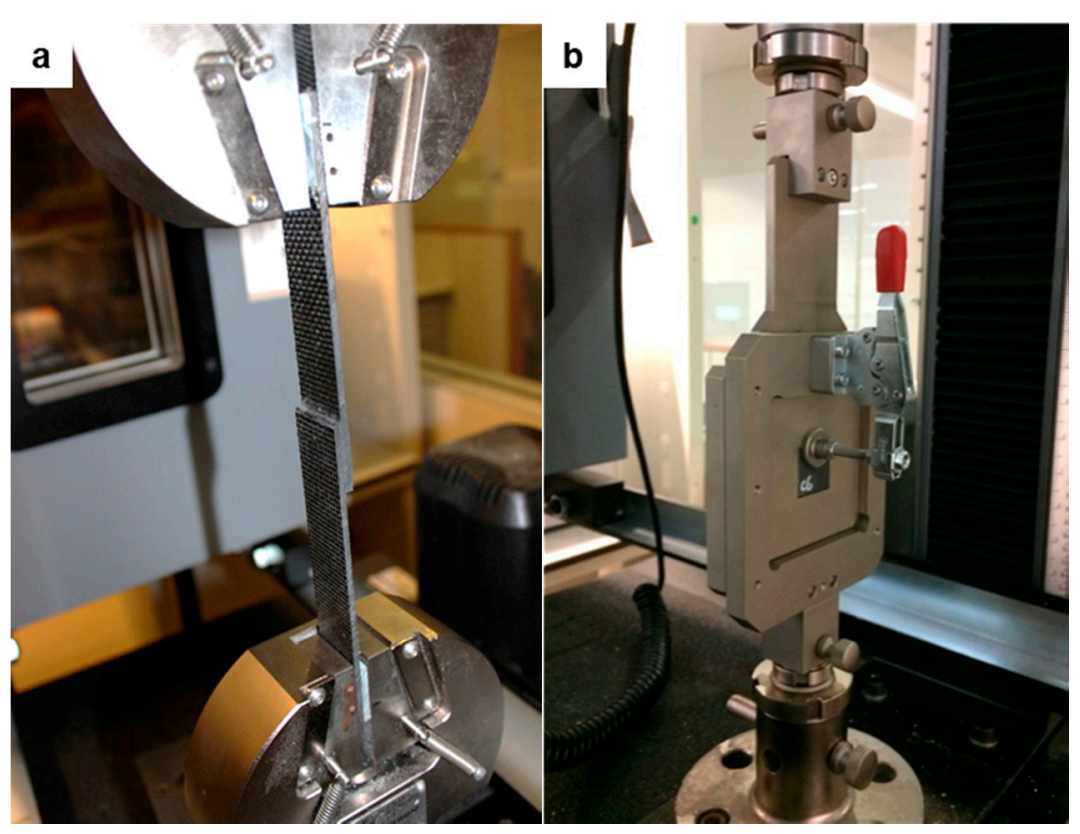

Figure 9. Tensile test setup for (a) single-lap shear specimen and (b) a block shear specimen.

\section{Results}

\subsection{Stress Analysis}

The results of the finite element analysis confirm what was predicted with the discussion of analytical models in Section 2. Shear and peel stresses for the single-lap shear geometry are shown in Figure 10 comparing different adherend-adhesive modulus ratios $\left(E_{r}\right)$. Shear stresses at the bondline edge are higher than at the center due to the differential shear, as discussed previously. The peel stresses are also significantly higher at the bondline edge than in the center of the bond. This effect is responsible for the delamination in FRP adherends, and demonstrates the difficulty with making conclusions about bond quality in such joints using this geometry. Trends are also visible with increasing $E_{r}$. A higher adherend modulus reduces edge-bending and produces a more consistent shear stress along the bondline and reduces the peel stress at the edges.
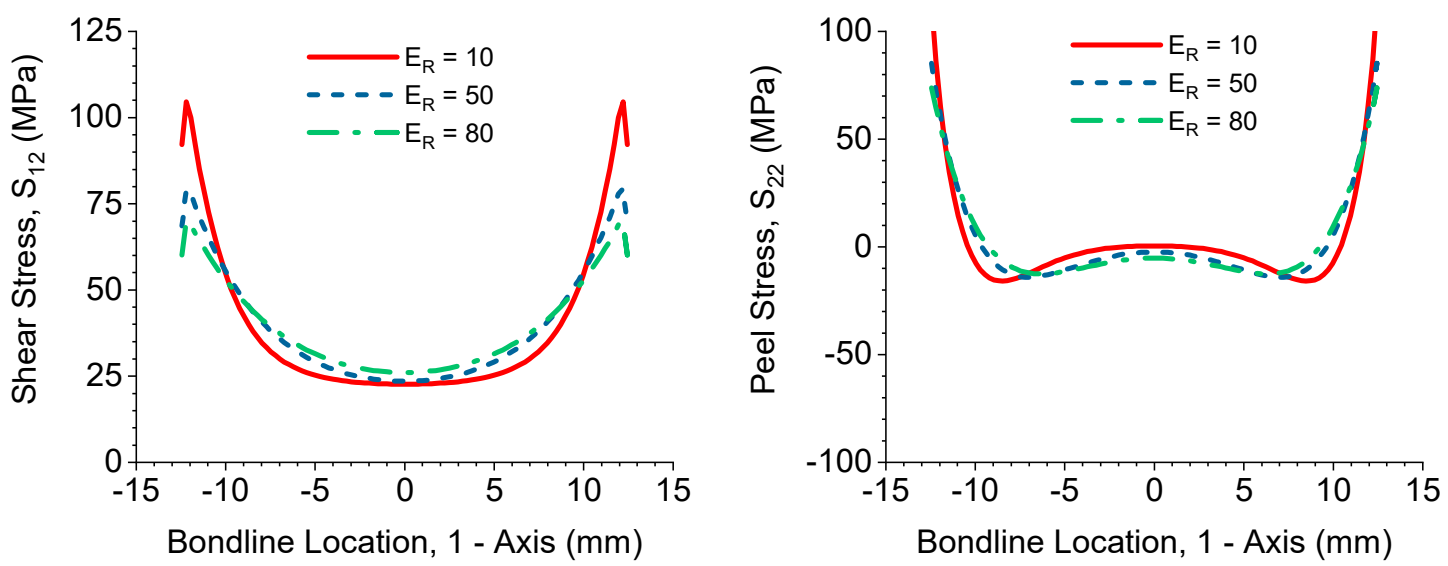

Figure 10. Shear stress and peel stress distributions along the bondline in a single-lap shear geometry for different modulus ratios, $E_{r}$

An identical analysis for the block shear geometry is shown in Figure 11. In block shear, the shear stress is still higher on the bondline edge for the lowest modulus ratio, but because the overlap length recommended by the ASTM standard for block shear is half that for the single-lap shear geometry, this effect is significantly reduced and a 
more consistent stress state is observed over the length of the bondline. As shown in Figure 11 (right), a shorter overlap length can be used because the peel stress does not play a role in block shear tests. Throughout the entire bondline length, the peel stresses are negative due to the compression of the block shear test fixture. This should prevent any premature delamination in the FRP adherend and provide more reliable test values that can be used for design purposes. Figure 12 provides a comparison of the difference in these test geometries, showing the ratio of peel stress to shear stress. The peel stress at the bondline edge in single-lap shear is clearly more influential on the measured joint strength than in block shear.
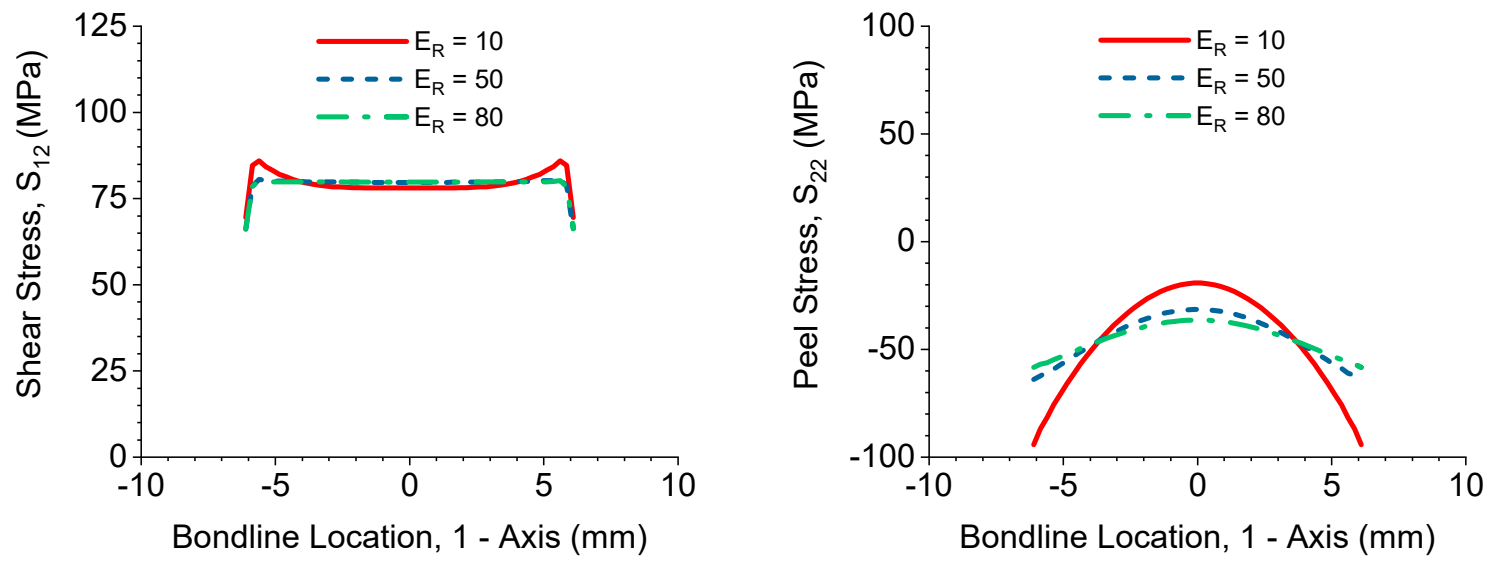

Figure 11. Shear stress and peel stress distributions along the bondline in a block shear geometry for different modulus ratios, $E_{r}$

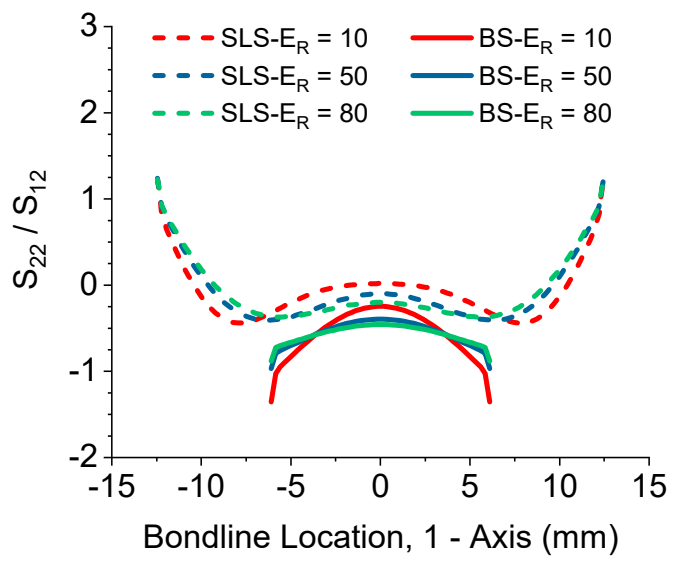

Figure 12. Comparison of the ratio of peel stress to shear stress for single-lap shear (SLS) and block shear (BS) geometries along the bondline.

\subsection{Shear Testing}

The results of the shear tests are shown in Figure 13 with error bars indicating the standard deviation over eight samples. For these, the NB-EP4030 material from Mitsubishi was used for the adherend. The DP190 adhesive had the highest average single lap shear strength, but also the highest standard deviation. This indicates issues with consistent application of adhesives in secondary bonding applications. EPX 82, the 3D printed adhesive, demonstrated a failure strength within one standard deviation of the commercial adhesive comparison. Both adhesive materials outperform the standard single-lap shear joint with the NB-EP4030 bonded directly to itself. This is due to the nature of the singlelap shear testing and the peeling stresses inherent in the test geometry. While combined loading conditions with normal stresses are useful and common in real applications, these results do not clearly indicate shear strength. 


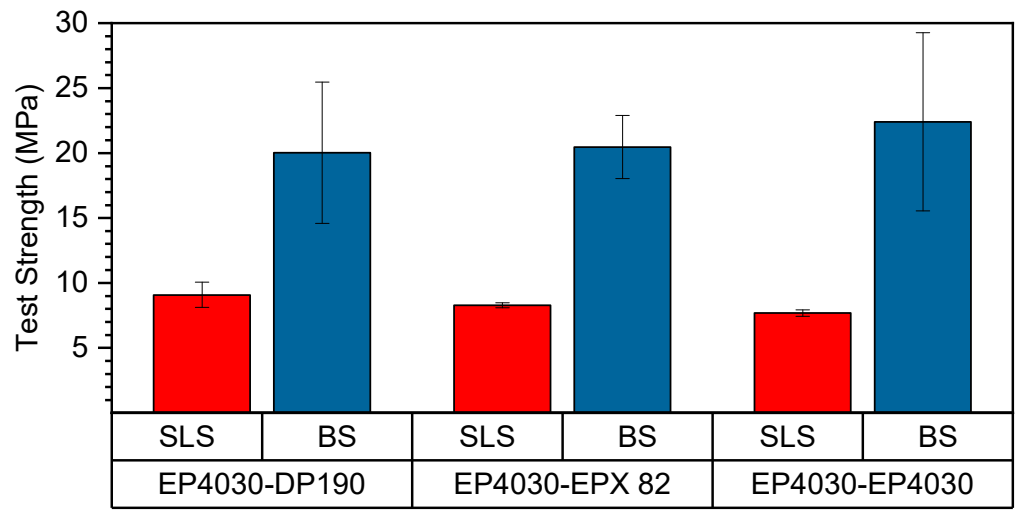

Figure 13. Comparison between single-lap shear (SLS) and block shear (BS) test results for the three different bonding materials.

Block shear testing was subsequently conducted to evaluate a primarily shear loading situation. The same adhesive materials were used for comparison in this test. The block shear tests show that the EPX 82 performs well in comparison with the commercial DP190 adhesive and is within one standard deviation of the bonding strength of the adherends themselves. Results for all combinations are at least a factor of two higher than the measured single lap shear strengths, indicating that the test configuration plays a significant role in the calculated bonding strength using Equation (9).

The results indicate a clear difference in the measured single-lap shear and block shear strength. While the results of single-lap shear tests suggest the commercial adhesive (DP190) provides the best bond quality, the results of block shear tests contradict these findings with the highest average strength demonstrated by direct prepreg-prepreg bonding. The differences between the two loading conditions explained in Section 3.1 and demonstrated in Section 5.1 provide insight into these results. Differences between the two test configurations are further illustrated by evaluating the failure modes (Figure 14). All single-lap shear specimens failed due to delamination of the composite adherend regardless of adhesive material. In contrast, all block shear specimens failed in a cohesive mode, better indicating the true adhesive strength.

a

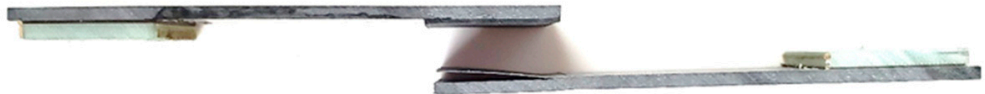

b
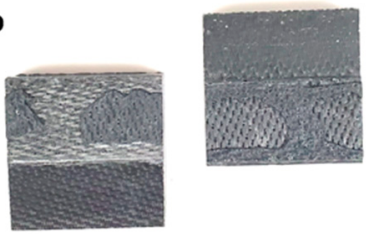

Figure 14. Demonstration of (a) a typical delamination failure in single-lap shear samples and (b) a cohesive failure in block shear samples.

\section{Discussion}

The single-lap shear test is a widely used method to measure the performance of adhesives and surface treatments. A significant challenge with this method is acquiring consistent and reliable engineering data due to complex stress states caused by the sample geometry and loading condition. Analytical models, such as those proposed by Goland and Reissner or Hart-Smith, demonstrate the effect of the edge-bending moment for singlelap shear in tension. The same analysis shows how the block shear test configuration 
effectively eliminates bending in the overlap and provide a better method for measuring shear strength.

Finite element analysis confirms the analytical models, showing that the peel stresses are nearly equivalent in magnitude to the shear stresses at the bondline edge in the singlelap shear configuration. In contrast, the shear stresses are dominant in block shear and peel stresses are all in compression due to the nature of the test fixture. The higher peel stresses in single-lap shear samples result in a much lower testing strength due to premature failure caused by delamination of the composite adherend. Block shear samples failed at test strengths over $100 \%$ higher than the single-lap shear samples, indicating the challenges of using single-lap shear geometry for acquiring reliable engineering data for pure-shear strength.

The analytical models suggest that the eccentricity, and therefore the peeling stress, can be reduced in lap shear testing by increasing the relative overlap length, and the practical improvements of modifying the current test standards for longer overlaps could be a compelling future study. However, if peeling stresses and adherend delamination are of interest, single-lap shear provides a valid test for comparing the strength of the adhesive to the interlaminar strength of the composite. While both test configurations may have their own merits in evaluating adhesive bonds in composite structures, which one to use will depend on which stresses will be most significant in the final application.

Author Contributions: Conceptualization, A.R., V.D., F.T., P.P., and T.A.O.; methodology, A.R., and V.D.; investigation, A.R., V.D., and F.T.; writing—original draft preparation, A.R., V.D., and F.T.; writing-review and editing, A.R., V.D., P.P., and T.A.O.; supervision, P.P. and T.A.O.; funding acquisition, P.P and T.A.O. All authors have read and agreed to the published version of the manuscript.

Funding: This material is based upon work supported by the National Science Foundation Graduate Research Fellowship Program under Grant No. DGE-1747503. Any opinions, findings, and conclusions or recommendations expressed in this material are those of the authors and do not necessarily reflect the views of the National Science Foundation. Additionally, support was also provided by the Graduate School and the Office of the Vice Chancellor for Research and Graduate Education at the University of Wisconsin-Madison with funding from the Wisconsin Alumni Research Foundation.

Institutional Review Board Statement: Not applicable.

Informed Consent Statement: Not applicable.

Data Availability Statement: The data presented in this study are available on request from the corresponding author.

Conflicts of Interest: The authors declare no conflict of interest. The funders had no role in the design of the study; in the collection, analyses, or interpretation of data; in the writing of the manuscript, or in the decision to publish the results.

\section{References}

1. Zhou, W.; Ai, S.; Chen, M.; Zhang, R.; He, R.; Pei, Y.; Fang, D. Preparation and thermodynamic analysis of the porous $\mathrm{ZrO} 2 /(\mathrm{ZrO} 2+\mathrm{Ni})$ functionally graded bolted joint. Compos. Part B Eng. 2015, 82, 13-22. [CrossRef]

2. Zhou, W.; Zhang, R.; Ai, S.; He, R.; Pei, Y.; Fang, D. Load distribution in threads of porous metal-ceramic functionally graded composite joints subjected to thermomechanical loading. Compos. Struct. 2015, 134, 680-688. [CrossRef]

3. Jones, R.M. Design of Composite Structures; Bull Ridge Publishing: Blacksburg, VA, USA, 2015.

4. Herzberg, E.F.; Chan, T.K.; Guo, S.; Morris, A.K.; Stevenson, A.; Stroh, R.F. Estimated Impact of Corrosion on Cost and Availability of DoD Weapon Systems_FY18 Update; LMI: Tysons, VA, USA, 2018.

5. Koch, G.; Varney, J.; Thompson, N.; Moghissi, O.; Gould, M.; Payer, J. International Measures of Prevention, Application, and Economics of Corrosion Technologies Study; NACE International: Houston, TX, USA, 2016.

6. Pocius, A.V. Adhesion and Adhesives Technology: An Introduction, 3rd ed.; Carl Hanser: Munich, Germany, 2012.

7. Da Silva, L.F.; Carbas, R.J.C.; Critchlow, G.W.; Figueiredo, M.A.V.; Brown, K. Effect of material, geometry, surface treatment and environment on the shear strength of single lap joints. Int. J. Adhes. Adhes. 2009, 29, 621-632.

8. Cognard, J.Y.; Créac'Hcadec, R.; Maurice, J. Numerical analysis of the stress distribution in single-lap shear tests under elastic assumption-application to the optimisation of the mechanical behaviour. Int. J. Adhes. Adhes. 2011, 31, 715-724. [CrossRef]

9. Adams, R.D.; Comyn, J.; Wake, W.C. Structural Adhesive Joints in Engineering, 2nd ed.; Chapman \& Hall: London, UK, 1997. 
10. Matthews, F.L.; Kilty, P.F.; Godwin, E.W. A review of the strength of joints in fibre-reinforced plastics Part 2. Adhesively bonded joints. Composites 1982, 13, 29-37. [CrossRef]

11. Adams, R.D. Strength predictions for lap joints, especially with composite adherends: A review. J. Adhes. 1989, 30, 219-242. [CrossRef]

12. Banea, M.D.; da Silva, L.F.M. Adhesively bonded joints in composite materials: An overview. Proc. Inst. Mech. Eng. Part L J. Mater. Des. Appl. 2009, 223, 1-18. [CrossRef]

13. ASTM International. ASTM D5856 Standard Test Method for Lap Shear Adhesion for Fiber Reinforced Plastic (FRP) Bonding; ASTM International: West Conshohocken, PA, USA, 2014.

14. ASTM International. ASTM D4501 Standard Test Method for Shear Strength of Adhesive Bonds Between Rigid Substrates by the Block-Shear Method; ASTM International: West Conshohocken, PA, USA, 2014.

15. Goland, M.; Reissner, E. The stresses in cemented joints. J. Appl. Mech. 1944, 11, A17-A27.

16. Hart-Smith, L.J. Adhesive Bonded Single Lap Joints, Contractor Report 112236; NASA: Washington, DC, USA, 1973.

17. Reddy, J.N. Theory and Analysis of Elastic Plates and Shells, 2nd ed.; CRC Press: Boca Raton, FL, USA, 2007.

18. Oplinger, D.W. Effects of adherend deflections in single lap joints. Int. J. Solid Struct. 1994, 31, 2565-2587. [CrossRef]

19. Li, G.; Lee-Sullivan, P. Re-visiting the beam models for adhesively bonded single-lap joints part 1: Comparison of bending moment predictions. Can. Aeronaut. Space J. 2006, 52, 149. [CrossRef]

20. Mitsubishi Chemical Carbon Fiber and Composites. 4030 Data Sheet; Mitsubishi Chemical Carbon Fiber and Composites: Irvine, CA, USA, 2017.

21. Mitsubishi Chemical Carbon Fiber and Composites. 301 Data Sheet; Mitsubishi Chemical Carbon Fiber and Composites: Irvine, CA, USA, 2016.

22. 3M Industrial Adhesives and Tapes Division. 3M Scotch-Weld Epoxy Adhesives DP190 Data Sheet; 3M Industrial Adhesives and Tapes Division: St. Paul, MN, USA, 2010.

23. EPX 82 Technical Data Sheet; 107172 rev. A.; Carbon: Redwood, CA, USA, 2018.

24. Austermann, J.; Redmann, A.; Dahmen, V.; Quintanilla, A.; Mecham, S.J.; Osswald, T.A. Fiber-reinforced composite sandwich structures by co-curing with additive manufactured epoxy lattices. J. Comput. Sci. 2019, 3, 53. [CrossRef]

25. Dahmen, V.; Redmann, A.; Austermann, J.; Quintanilla, A.; Mecham, S.J.; Osswald, T.A. Fabrication of hybrid composite T-joints by co-curing with 3D printed dual cure epoxy. Compos. Part B Eng. 2020, 183, 107728. [CrossRef] 